\title{
Article \\ Evaluation of Non-Encapsulated and Microencapsulated Lactic Acid Bacteria
}

\author{
Mihaela Dumitru $^{1, *(\mathbb{D})}$, Dan Cristian $\operatorname{Vodnar}^{2} \mathbb{D}$, Simon Elemer ${ }^{2} \mathbb{D}$, Georgeta Ciurescu ${ }^{1} \mathbb{D}$, Mihaela Habeanu $^{1} \mathbb{D}$, \\ Ionut Sorescu ${ }^{1,3} \mathbb{D}$, Sergiu Emil Georgescu 4 (D) and Andreea Dudu 4 (D)
}

1 Department of Animal Nutrition and Biotechnology, National Research and Development Institute for Biology and Animal Nutrition (IBNA), 077015 Balotesti, Romania; ciurescu@ibna.ro (G.C.); mihaela.habeanu@ibna.ro (M.H.); ionut.sorescu@idah.ro (I.S.)

2 Department of Food Science, University of Agricultural Science and Veterinary Medicine, Calea Mănăstur, No. 3-5, 400372 Cluj-Napoca, Romania; dan.vodnar@usamvcluj.ro (D.C.V.); simon.elemer@usamvcluj.ro (S.E.)

3 Institute for Diagnosis and Animal Health, 050557 Bucharest, Romania

4 Department of Biochemistry and Molecular Biology, Faculty of Biology, University of Bucharest, Splaiul Independentei, No. 91-95, 050095 Bucharest, Romania; sergiu.georgescu@bio.unibuc.ro (S.E.G.); andreea.dudu@bio.unibuc.ro (A.D.)

* Correspondence: mihaela.dumitru@ibna.ro

check for updates

Citation: Dumitru, M.; Vodnar, D.C.; Elemer, S.; Ciurescu, G.; Habeanu, M.; Sorescu, I.; Georgescu, S.E.; Dudu, A. Evaluation of Non-Encapsulated and Microencapsulated Lactic Acid Bacteria. Appl. Sci. 2021, 11, 9867. https://doi.org/10.3390/app11219867

Academic Editors:

Francesca Raganati and Alessandra Procentese

Received: 15 September 2021

Accepted: 19 October 2021

Published: 22 October 2021

Publisher's Note: MDPI stays neutral with regard to jurisdictional claims in published maps and institutional affiliations.

Copyright: (c) 2021 by the authors. Licensee MDPI, Basel, Switzerland. This article is an open access article distributed under the terms and conditions of the Creative Commons Attribution (CC BY) license (https:// creativecommons.org/licenses/by/ $4.0 /)$.

\begin{abstract}
A total of 15 strains of lactic acid bacteria (LAB) were isolated from the broiler chicken's gastrointestinal tract. All isolates were phenotypical and genetically identified. Among these isolates, only six were biochemical (API $50 \mathrm{CHL}$ and ABIS soft) and genetically (16S rRNA sequencing) confirmed as Lactobacillus acidophilus, Limosilactobacillus fermentum, Levilactobacillus brevis, and Ligilactobacillus salivarius. Probiotic properties, including tolerance to $\mathrm{pH}(\mathrm{pH} 2.0$ and 3.0), bile salts $(0.3 \%$ oxgall), hemolysis activity, and antibiotic susceptibility, were evaluated. Three isolates of the latter isolates showed high resistance at low $\mathrm{pH}$ values $(73.74 \%$ to $98.20 \%)$ and bile salt concentrations (77.89\% to $99.49 \%$ ). The antibiotic test presented 100\% resistance of LAB to gentamicin, lincomycin, enrofloxacin, and streptomycin lower than the $0.5 \mathrm{~mm}$ inhibition zone diameter. Selected strains (L. acidophilus IBNA 64, L. salivarius IBNA 33, and L. salivarius IBNA 41) were exposed to the spraydrying process based on observable probiotic potential. A maltodextrin-glucose solution was used as a thermoprotectant. After spray drying, a reduction in strain viability was noted $\left(10^{8}\right.$ to $\left.10^{4} \mathrm{CFU} / \mathrm{g}\right)$. In conclusion, only L. salivarius (IBNA 33 and IBNA 41) could be used as a possible probiotic, and further studies are needed to ensure their safe application in the animal nutrition field with beneficial effects for improving performance and pathogen microorganism control from intestines equilibrating the microbiota composition.
\end{abstract}

Keywords: Lactobacillus; probiotic; spray drying; viability; broiler

\section{Introduction}

Since 2006, the European Union has banned the addition of antibiotics in animal feed due to the increase in resistance among microorganisms and the accumulation of residues in food products. As an alternative to antibiotics, probiotics contain one or more strains of microorganisms and play a central role in animal feed supplementation [1].

Probiotics are bacteria defined as "live microorganisms which, when administered in adequate amounts, confer a health benefit to increase the immunity of the host" [2]. Probiotics are used in both animal and human nutrition as they provide a natural, safe, and effective barrier against pathogens [3-5]. The most common microorganisms used as probiotics are Gram-positive bacteria such as Lactobacillus, Streptococcus, Lactococcus, Pediococcus, Enterococcus, Bifidobacterium, and Bacillus [6,7].

The supplementation of probiotics in poultry feed has garnered substantial attention due to their benefits on health, modifications on villus intestinal epithelium [8], growth performance, feed conversion ratio, increase of intestinal length, decrease of fat abdomen 
percentage [9], and reduction of gastrointestinal disorders such as diarrhea [10]. Ensuring adequate amounts of probiotics at the time of feeding is a real challenge, because several factors during processing and storage can disturb the viability of probiotic bacteria [11]. For example, low acidic conditions, the presence of trypsin, pepsin, and bile salts in the stomach [12], transition through the gastrointestinal tract (GIT), storage conditions (oxygen, high temperature, $\mathrm{pH}$ changes, relative humidity) and antimicrobial substances, have all been implicated in the loss of probiotic cells viability [13].

According to the International Dairy Federation (IFD), a good probiotic must present at least $10^{7} \mathrm{CFU} / \mathrm{g}$ until used. Therefore, Mahmoud et al. [10] recommended a minimum dose level of probiotic bacteria of at least $10^{6} \mathrm{CFU} / \mathrm{g}$ at the time of ingesting to confer beneficial health effects. Similarly, the Canadian Food Inspection Agency (CFIA) [14] affirmed that a probiotic product should contain a minimum of $1 \times 10^{9} \mathrm{CFU} / \mathrm{g}$.

Microencapsulation is a technique with the ability to protect sensitive microorganisms such as LAB strains against loss of cell viability during GIT passage, through entrapment within a matrix of biopolymeric material [11,15]. As protection from external damaging factors, in microencapsulation, the semipermeable membrane that surrounds the liquid core is required to preserve cell viability during processing and storage $[7,16]$.

Spray drying is one of the most popular and appropriate encapsulating techniques, due to its cost-effectiveness, rapidity, and reproducibility $[17,18]$. The addition of protectants to the culture medium before drying diminishes the harmful effects of heat treatments. Thermoprotectants like non-fat milk solids, starch, sugars (glucose, lactose, trehalose, inulin, dextrose, maltodextrin, sorbitol, etc.) are involved to stimulate the growth of the organism by improving bacteria viability during drying and storage conditions [19]. Furthermore, microencapsulation coats the active ingredients in the form of solid, liquid, or gaseous substances (the core) with a polymeric material layer (the shell), involving microparticles from the micrometer to the millimeter range. In addition, microencapsulation can modify the physical characteristics by changing liquids into a solid state to enhance its administration property [17] and to protect the probiotics from degradation $[14,18,20]$.

The genus Lactobacillus includes Gram-positive, fermentative, facultatively anaerobic, catalase negative, cocci or rod bacteria and non-spore-forming microorganisms [21]. Species from the Lactobacillus group are a large population found in the intestinal tract, and act as an indicator of a healthy microbiota. Due to the capacity to synthesize lactic acid as the major metabolic end-product of carbohydrate fermentation, and other products such as acetate, ethanol, $\mathrm{CO}_{2}$, some LAB can inhibit the growth of spoilage agents [21,22]. For example, in poultry production, LAB represent the most commonly used probiotic agents [17]. Moreover, the oral supplementation of broiler chickens based on LAB probiotics (higher doses starting from $10^{7}-10^{9} \mathrm{CFU} / \mathrm{mL} / \mathrm{bird} /$ day) increased the total LAB bacteria in the GIT, villus height with an enhancement of the chickens' performances [23]. It is very important to use lactic acid bacteria isolated from the same animal category and to use them in the same species origin.

Consequently, this study aimed to isolate, identify, characterize and assess the benefits of some LAB from broiler chickens GIT and investigate their probiotic properties (tolerance to low $\mathrm{pH}$ and bile salts, hemolytic activity, antibiotic susceptibility). The selected strains based on higher viability were subject to spray drying to be used as possible candidates in animal nutrition.

\section{Materials and Methods}

\subsection{Ethics Statement}

Healthy broiler chickens, housed in the Experimental Biobase of National ResearchDevelopment Institute for Biology and Animal Nutrition (IBNA) Balotesti were randomly selected for this study at different sampling times. Birds were treated in accordance with Romanian Legislation (law No. 305/2006) and the experimental procedure was approved by the Committee of Ethics for Animal studies of IBNA Balotești, Romania. The in vitro assessment was performed at the Biotechnology Laboratory of IBNA Balotesti 
in collaboration with the University of Agricultural Sciences and Veterinary Medicine (USAMV) Cluj, the Fermentative Biotechnologies Department.

\subsection{Isolation and Phenotypical Identification of Lactic Acid Bacteria}

A total of $15 \mathrm{LAB}$ strains were isolated from broiler chickens GIT (ileum and cecum). Sorescu et al. [23] method was applied. Sample preparation: $1 \mathrm{~g}$ intestinal digesta per capita from fifteen chicks (Cobb 500, 26 and 45-day-old) was homogenized with $7 \mathrm{~mL}$ BHI (Brain Heart Infusion, Oxoid Basingstoke, Hampshire, UK) broth and $2 \mathrm{~mL}$ glycerol, and immediately frozen at $-20^{\circ} \mathrm{C}$. After defrosting, the content of ileum and cecum were serially diluted in phosphate-buffered saline pH 7.0 (PBS, Dulbecco A; Oxoid Livingstone Ltd., London, England) and spread on three Petri dishes with Man, Rogosa, Sharpe agar (MRS, Oxoid CM0361), followed by anaerobic incubation at $37^{\circ} \mathrm{C}$ for $24-48 \mathrm{~h}$ (Oxoid jar with Anaerogen $2.5 \mathrm{~L}$ ). After incubation, colonies were sampled and further purified on MRS agar media. The isolates were evaluated for physiological traits (i.e., colonies morphological, Gram-positive, catalase test, rod-shaped). Lactobacillus isolates were identified using the API 50 CHL kit (BioMérieux, Marcy l'Etoile, France), API 50 CHL V 5.1 and ABIS online soft according to manufacturer's instructions [24].

\subsection{Molecular Identification of Lactic Acid Bacteria}

Total genomic DNA of Lactobacillus strains was extracted using a Wizard Genomic DNA Purification Kit (Promega, Corporation, WI, USA) according to the manufacturer's instructions. The quality and quantity were checked using a NanoDrop 8000 spectrophotometer (ThermoFisher Scientific, Wilmington, DE, USA). Preliminary characterization of isolated strains was performed based on the phenotype traits. Molecular identification of lactic acid bacteria was done by sequence analysis of a 16S rRNA gene (16S rRNA). Two pairs of primers were used to amplify and sequence different regions of the gene. The forward and reverse primers Lac1 F ( $5^{\prime}$-AGCAGTAGGGAATCTTCCA- $\left.3^{\prime}\right)$ and Lac1 R (5'-ATTYCACCGCTACACATG-3') were designed accordingly to Vanhoutte et al. [25] with some minor modifications to amplify a $345 \mathrm{bp}$ fragment from variable regions V2-V4 of $16 \mathrm{~S}$ rRNA gene. A second pair of primers, 27F (5'-AGAGTTTGATCCTGGCTCAG-3') and 1492R (5'-GGTTACCTTGTTACGACTT- $3^{\prime}$ ) were used to amplify and sequence the complete region of $16 \mathrm{~S}$ rRNA gene when the sequencing of $345 \mathrm{bp}$ fragment amplified with the primers Lac1F/R showed to be inconclusive. In the both cases, the PCR was performed with an AmpliTaq polymerase kit (Applied Biosystems). Each PCR mixture ( $25 \mu \mathrm{L})$ contained $2.5 \mu \mathrm{L}$ PCR buffer 10X, $1.5 \mu \mathrm{L} 25 \mathrm{mM} \mathrm{MgCl} 2,2 \mu \mathrm{L}$ dNTPs mix (containing each $\mathrm{dNTP}$ at a concentration of $2 \mathrm{mM}$ ), $0.5 \mu \mathrm{L}$ of each primer (with concentration 20 pmols $/ \mu \mathrm{L}$ ); $0.1 \mu \mathrm{L}$ of AmpliTaq polymerase $(5 \mathrm{U} / \mu \mathrm{L})$ and the corresponding volumes of sterile Milli-Q water and DNA diluted solution.

Amplification was performed in a Veriti ${ }^{\mathrm{TM}}$ 96-Well Thermal Cycler (ThermoFisher Scientific) programmed for $10 \mathrm{~min}$ at $95^{\circ} \mathrm{C}$ (initial denaturation) and 30 cycles of $30 \mathrm{~s}$ at $95^{\circ} \mathrm{C}$ (denaturation), $30 \mathrm{~s}$ at $60^{\circ} \mathrm{C}$ (annealing), $1 \mathrm{~min}$ at $72{ }^{\circ} \mathrm{C}$ (extension) and $10 \mathrm{~min}$ at $72{ }^{\circ} \mathrm{C}$ (final extension). Reaction products were resolved by electrophoresis in $2 \%(w / v)$ agarose gels and visualized by ethidium bromide staining. The sequencing of the PCR products was done by using the BigDye Terminator v3.1 Cycle Sequencing Kit (Applied Biosystems, Wilmington, DE, USA). The automated sequencing of both strands of the PCR product was done on an ABI Prism 3130 automated gene sequencer (Applied Biosystems). The Basic Alignment Search Tool (BLAST) tool (http:/ /blast.ncbi.nlm.nih.gov / Blast.cgi, accessed on 11 October 2021) was used to assess the degree of similarity of our sequences with similar 16S rRNA sequences from the GenBank database. BLAST is an online program belonging to NCBI (National Center for Biotechnology Information) to establish the hits of subjects sequences deposited in the international nucleotide databases (e.g., GenBank, EMBL etc.) giving the best matching with the query sequence [26]. 


\subsection{Preservation of Bacterial Strains and Viability Determination}

Lactobacillus isolates were stored in MRS broth at $-80{ }^{\circ} \mathrm{C}$, supplemented with $20 \%$ $(v / v)$ sterile glycerol. To determine the growth rate, the isolates were cultivated on MRS media at $37^{\circ} \mathrm{C}$, for $48 \mathrm{~h}$, in anaerobic conditions. The results were expressed as $\log 10 \mathrm{CFU}$ per gram.

\section{5. $p H$ Low Tolerance}

The overnight cultures of Lactobacillus isolates (7-8 Log UFC / $\mathrm{mL}$ in PBS, $\mathrm{pH}=7.2 \pm 0.2$ ) were grown in anaerobic conditions. For each LAB strain, $1 \mathrm{~mL}$ of fresh culture was suspended in $9 \mathrm{~mL}$ of MRS broth adjusted at $\mathrm{pH} 3.0$ and 2.0 with $1 \mathrm{~N} \mathrm{HCl} \mathrm{37 \%}$ before autoclaving. At different time intervals $(0,1: 30$, and $3 \mathrm{~h})$, the viability of the strains was taken and serially diluted up to $10^{-10}$, seeded on MRS agar and incubated at $37^{\circ} \mathrm{C}$, anaerobically for $48 \mathrm{~h}$. The culture grown in MRS broth ( $\mathrm{pH} 7.2 \pm 0.2)$ was used as the control test [27].

\subsection{Bile Salts Tolerance}

The overnight cultures (7-8 $\log \mathrm{CFU} / \mathrm{mL}$ ) were centrifugated at $7000 \times g$ for $10 \mathrm{~min}$ at $4{ }^{\circ} \mathrm{C}$. The cells from $100 \mathrm{~mL}\left(24 \mathrm{~h} \mathrm{MRS} \mathrm{culture,} 37^{\circ} \mathrm{C}\right)$ were collected and washed three times in PBS and resuspended in fresh MRS broth containing 0.3\% bile salts (oxgall, Oxoid, $w / v)$. After $0,1: 30$, and $3 \mathrm{~h}$ of incubation at $37^{\circ} \mathrm{C}$ for $48 \mathrm{~h}$, in anaerobic conditions, the viable counts were determined by serial dilution in sterile PBS (up to $10^{-10}$ ) on MRS agar plates. The control sample was represented by MRS culture $(\mathrm{pH}=6.5 \pm 0.2)$, without added bile salts. The cell's enumeration was determined by the total plate count method (TPC, CFU/mL), converted to the logarithmic value.

The survival percentage for $\mathrm{pH}$ and bile salts was done using the method reported by Ritter et al. [28], as follows:

$$
\text { Survival }(\%)=\frac{\text { Log number of cells survived }\left(\frac{C F U}{m L}\right) \times 100}{\text { Log number of initial cells inoculated }\left(\frac{C F U}{m L}\right)}
$$

\subsection{Hemolysis Test}

Blood agar plates [Trypticase soy agar (TSA, Sanimed) containing 5\% $(w / v)$ sheep blood] were used to test hemolysis activity. Interpretation was followed after incubation at $37^{\circ} \mathrm{C}$, for $24 \mathrm{~h}[29]$.

\subsection{Antibiotic Susceptibility}

The antibiotic susceptibility of isolates to different antibiotics (Oxoid, Basingstoke, Hampshire, UK) including tetracycline (TE, $30 \mu \mathrm{g})$, vancomycin (VA, $30 \mu \mathrm{g})$, amoxicillin (AMX, $25 \mu \mathrm{g}$ ), clindamycin (CLI, $2 \mu \mathrm{g}$ ), erythromycin (E, $15 \mu \mathrm{g})$, ciprofloxacin (CIP, $5 \mu \mathrm{g})$, gentamicin $(\mathrm{CN}, 10 \mu \mathrm{g})$, amikacin (AMK, $25 \mu \mathrm{g})$, chloramphenicol (C, $30 \mu \mathrm{g})$, kanamycin $(\mathrm{K}, 30 \mu \mathrm{g})$ and oxacillin (OXA, $1 \mu \mathrm{g})$ was determined by the agar disc diffusion method on MRS agar plates. One hundred microliters of each bacterial suspension with a turbidity equivalent to McFarland Standard 1 and an optical density of 0.5 at $\lambda 600 \mathrm{~nm}$ (corresponding to about $1 \times 10^{8} \mathrm{CFU} / \mathrm{mL}$ ) was spread on the surface of a Petri dish using a sterile cotton swab. After incubation of isolates at $37^{\circ} \mathrm{C}, 24 \mathrm{~h}$ in anaerobic conditions, the diameter of the growth inhibition was measured with a ruler in $\mathrm{mm}$. The results were read as sensitive $(S)$ and resistance $(R)$ based on the diameter of the inhibition zone [30].

\subsection{Bioreactor Batch and Fermentation Process}

Initially, $200 \mathrm{~mL}$ of pre-culture broth (inoculum) was inoculated with a $24 \pm 2 \mathrm{~h}$ colony of $10^{10} \mathrm{CFU} / \mathrm{mL}$, at $37^{\circ} \mathrm{C}$ for $24 \mathrm{~h}$ and $150 \mathrm{rpm}, \mathrm{pH}=6.5 \pm 0.2$. The inoculum from each selected strain was used as starter for further fermentation. The fermentation medium was prepared in a $5 \mathrm{~L}$ bioreactor (Eppendorf, type BioFlo 320, one unit, Hamburg, Germany) containing $2 \mathrm{~L}$ of working final media. The fermentation process was fitted with 
$\mathrm{pH}$, temperature sensors, and a rotation speed control which were maintained constant at $6.5 \pm 0.2,37^{\circ} \mathrm{C}$, and $150 \mathrm{rpm}$. The $\mathrm{pH}$ value was adjusted automatically by a peristaltic pump adding $40 \% \mathrm{NaOH}(w / v)$, respectively $1 \mathrm{~N} 37 \% \mathrm{HCl}(v / v)$. Antifoam 204 agent sterilized silicone oil (Sigma-Aldrich) was added as required $(0.01 \%, v / v)$.

\subsection{Spray Drying Technique Using Maltodextrin and Glucose and Cell Viability}

A BÜCHI Mini Spray Dryer B-290 Swiss-made (Switzerland) was used for microencapsulation of LAB strains. Maltodextrin-glucose solution ( $24 \%$ maltodextrin and $4 \%$ glucose, $w / v)$ was prepared in distilled water and sterilized by autoclavation $\left(121^{\circ} \mathrm{C}\right.$ for $\left.15 \mathrm{~min}\right)$. After $24 \mathrm{~h}$ of incubation at $37^{\circ} \mathrm{C}$ and $150 \mathrm{rpm}$ in the bioreactor, the bacterial culture was centrifuged at $8000 \mathrm{rpm}$ for $10 \mathrm{~min}$ at $4{ }^{\circ} \mathrm{C}$. After discarding the supernatant, the cell suspension (biomass) was washed three times with sterile distilled water. The pellet cell was then resuspended aseptically into the sterile mixed solution. During spray drying, the culture solution was homogenized with magnetic stirring, at room temperature, under continuous agitation. The operating conditions were: inlet air temperature $126 \pm 3{ }^{\circ} \mathrm{C}$, outlet air temperature $66 \pm 3^{\circ} \mathrm{C}$, volume flow of $15 \mathrm{~mL} / \mathrm{min}$, compressor air pressure of $0.6 \mathrm{MPa}$, and drying air flow rate of $0.04 \mathrm{~m}^{3} / \mathrm{h}$.

Serial dilutions were done in PBS ( $\mathrm{pH}=7 \pm 0.2)$ for evaluating the survival of microencapsulated bacteria (L. acidophilus IBNA 64, L. salivarius IBNA 33, and L. salivarius IBNA 41). Briefly, $1 \mathrm{~g}$ of powder strain was dissolved in $9 \mathrm{~mL}$ MRS broth $(\mathrm{pH}=6.5 \pm 0.2)$ and vortexed till complete dissolution. Serially dilutions in $9 \mathrm{~mL}$ PBS from spray-dried powder were completed and plated out on MRS agar by incubation at $37^{\circ} \mathrm{C}, 48 \mathrm{~h}$, in anaerobic conditions. $\mathrm{LAB}$ enumeration was expressed as $\mathrm{CFU} /$ gram of microcapsule (Log CFU/g).

The equation from Bhagwat et al. [18] was used to calculate encapsulation efficiency (EE):

$$
\mathrm{EE}=100 \times \mathrm{Nr} / \mathrm{Nf}
$$

where, $\mathrm{Nr}=\mathrm{Log} \mathrm{CFU} / \mathrm{mL}$ before spray drying; $\mathrm{Nf}=\mathrm{Log} \mathrm{CFU} / \mathrm{mL}$ after spray drying.

\subsection{Probiotic Powder Storage}

The powder was stored under aerobic conditions at room temperature $\left(25^{\circ} \mathrm{C}\right)$ in a Ziplock pouch. Periodically, the viability of the encapsulated LAB was verified on days 0 , $7,14,21,27,35,42,49,56$, and 62 of storage. One gram of powder was blended with $9 \mathrm{~mL}$ MRS broth on a magnetic agitator at $200 \mathrm{rpm}$ for $30 \mathrm{~min}$. The suspension was diluted in PBS buffer and spread onto MRS agar follow by incubation at $37^{\circ} \mathrm{C}, 48 \mathrm{~h}$. Labs colonies were counted and expressed as CFU/gram.

\subsection{Total Coliforms Count}

Following Salman and Hamad [31], the Lauryl sulfate-tryptose broth (BK010HA), was used as selective enrichment media for the presumptive detection of Coliforms count. Decimal dilutions were done in PBS $\left(10^{1}-10^{5}\right)$. Each Lauryl Tryptose tube contains a Durham tube. One $\mathrm{mL}$ of each dilution was pipetted into 5 Lauryl Tryptose tubes, followed by incubation at $37^{\circ} \mathrm{C}$ for $48 \mathrm{~h}$, and then examined for gas production in the Durham tubes. Positive test (gassing) in Lauryl Tryptose with Durham tubes was homogenized and $1 \mathrm{~mL}$ of suspension was transferred in another tube with brilliant green bile broth at $37^{\circ} \mathrm{C}$. Broth medium modification (gas formation with slight turbidity in Durham's tubes) was registered as a positive test.

Results were computed using the McCrady table (MPN—-the most probable number of bacteria) based on a combination of confirmed positive tubes for three consecutive dilutions.

\subsection{Statistical Analysis}

Statistical analysis of the data was compared using variance analysis (ANOVA) with STATVIEW for Windows (SAS, version 6.0). The results are reported as mean values and standard error of the mean (SEM), the differences between means considered statistically significant at $p<0.05$, using the Tukey LSD test for the untitled compact variable. The 
graphics for bacterial population before and after the spray drying process and the storage stability during 62 days at room temperature $\left(25^{\circ} \mathrm{C}\right)$ were generated using SigmaPlot V.11 software (San Jose, CA, USA).

\section{Results}

\subsection{Isolation and Phenotypical Identification of Lactic acid Bacteria}

LAB was isolated from broiler chickens intestinal digesta (ileum and cecum content, Table 1).

Table 1. The origin of Lactobacillus strains existence in broiler chickens GIT.

\begin{tabular}{|c|c|}
\hline Strains/Code IBNA & Area of Intestinal Content and Age of Broiler Chickens \\
\hline \multicolumn{2}{|c|}{ L. acidophilus biotype 3, IBNA } \\
\hline 26 & Ileum, 26 d-old \\
\hline 27 & Cecum, 26 d-old \\
\hline 51 & Ileum, 45 d-old \\
\hline L. acidophilus biotype 1, IBNA 64 & Ileum, 45 d-old \\
\hline \multicolumn{2}{|l|}{ L. brevis biotype 2 , IBNA } \\
\hline 24 & Cecum, 26 d-old \\
\hline 50 & Ileum, $45 \mathrm{~d}$-old \\
\hline \multicolumn{2}{|c|}{ L. fermentum biotype 1, IBNA } \\
\hline 25 & Ileum, 26 d-old \\
\hline 37 & Cecum, 45 d-old \\
\hline $\begin{array}{l}56 \\
57\end{array}$ & $\begin{array}{l}\text { Cecum, } 45 \text { d-old } \\
\text { Ileum, } 45 \text { d-old }\end{array}$ \\
\hline \multicolumn{2}{|r|}{ L. salivarius, IBNA } \\
\hline 29 & Cecum, 26 d-old \\
\hline $\begin{array}{l}33 \\
41\end{array}$ & Ileum, 26 d-old \\
\hline \multicolumn{2}{|c|}{ L. plantarum biotype 1 , IBNA } \\
\hline $\begin{array}{l}48 \\
61\end{array}$ & Ileum, 45 d-old \\
\hline
\end{tabular}

A total of 15 Lactobacillus isolates were selected for identification and confirmation. The results of phenotypical identification showed that 15 isolates belonged to the Lactobacillus genus (Table S1). All samples presented typical morphological traits of LAB and were grown in anaerobic conditions. Gram's reaction was found positive and was determined after Gram staining by light microscopy (blue-purple in color). The isolates were performed for the catalase test and $\mathrm{LAB}$ were found to be catalase negative (no effervescence was observed on the glass slide). As is well known, catalase is an enzyme that breaks down the $\mathrm{H}_{2} \mathrm{O}_{2}$ into oxygen and water [31]. The presence of oxygen was observed by visible bubbles.

Table S1 shows the percentage of identification for LAB strains using API 50 CHL kit, respectively ABIS online similarity. API $50 \mathrm{CHL}$ identification is a representative system that shows the LAB carbohydrates fermentation profile.

The strains identified as L. acidophilus (biotype 3 IBNA 26 and biotype 1 IBNA 64), L. brevis (biotype 2 IBNA 24 and IBNA 50), L. fermentum (biotype 1 IBNA 25, IBNA 37, IBNA 56, and IBNA 57), L. salivarius (IBNA 29, IBNA 33, and IBNA 41), L. plantarum (biotype 1 IBNA 48 and IBNA 61), were isolated from 26, respectively $45 \mathrm{~d}$-old broiler chickens.

In Table S1, the isolates produced different results when reacted with the 50 substrates from the API 50 CHL kit.

\subsection{Molecular Identification of Lactic Acid Bacteria}

The LAB strains based on phenotypical characteristics were exposed to molecular confirmation. From the total of 15 isolates strains that were biochemically identified (API $50 \mathrm{CHL}$ and Abis online), only 12 isolates were confirmed by $16 \mathrm{~S}$ rRNA analysis when 
the primers Lac1F/ Lac1R were used as following: L. acidophilus (IBNA 26, IBNA 64, 2/15 isolates; 13.33\%), L. fermentum (IBNA 37, 1/15 isolates; 6.66\%), L. salivarius (IBNA 29, IBNA 33, IBNA 41, 3/15 isolates; 20\%), species belonging to Lactobacillus genus (IBNA 24, IBNA 25, IBNA 56, IBNA 57, IBNA 48, IBNA 61, 6/15 isolates; 40\%) (Table 2).

Table 2. Molecular identification of Lactobacillus strains from broiler chickens intestinal content.

\begin{tabular}{|c|c|c|c|}
\hline \multirow[t]{2}{*}{$\begin{array}{l}\text { Total Number } \\
\text { of Isolates }\end{array}$} & \multicolumn{3}{|l|}{ Identification Technique } \\
\hline & API 50 CHL & $\begin{array}{l}\text { 16S rRNA Gene Fragment } \\
\text { Sequencing (Primers Lac1F/Lac1R) }\end{array}$ & $\begin{array}{l}\text { 16S rRNA Gene Fragment } \\
\text { Sequencing (Primers 27F/1492R) }\end{array}$ \\
\hline \multirow{20}{*}{15} & \multicolumn{3}{|l|}{ L. acidophilus biotype 3 IBNA } \\
\hline & 26 & L. acidophilus & \\
\hline & 27 & -identified as L.johnsonii & identified as L.johnsonii \\
\hline & 51 & -identified as L.johnsonii & identified as L.johnsonii \\
\hline & $\begin{array}{l}\text { L. acidophilus biotype } 1 \text {, } \\
\text { IBNA } 64\end{array}$ & L. acidophilus & \\
\hline & \multicolumn{3}{|l|}{ L. brevis biotype 2 , IBNA } \\
\hline & 24 & Lactobacillus spp. & L. brevis \\
\hline & 50 & Lactobacillus spp. & L. brevis \\
\hline & \multicolumn{3}{|c|}{ L. fermentum biotype 1 , IBNA } \\
\hline & 25 & Lactobacillus spp. & L. fermentum \\
\hline & 37 & L. fermentum & \\
\hline & 56 & Lactobacillus spp. & L. fermentum \\
\hline & 57 & Lactobacillus spp. & L. fermentum \\
\hline & \multicolumn{3}{|l|}{ L. salivarius, IBNA } \\
\hline & 29 & L. salivarius & \\
\hline & 33 & L. salivarius & \\
\hline & 41 & L. salivarius & \\
\hline & \multicolumn{3}{|l|}{ L. plantarum biotype 1 , IBNA } \\
\hline & 48 & Lactobacillus spp. & L. plantarum \\
\hline & 61 & Lactobacillus spp. & L. plantarum \\
\hline
\end{tabular}

Thus, the BLAST analysis used to achieve the molecular diagnostic of LAB strains included in this study revealed a $100 \%$ identification with similar 16 S rRNA sequences from GenBank in the case of previously mentioned strains.

However, for other strains, identification was possible only to the Lactobacillus genus level, or did not confirm the characterization based on phenotypical features as was the case of two samples (IBNA 27 and IBNA 51) of L. acidophilus that were classified as L. johnsonii on a molecular basis. To eliminate any ambiguity, and for an accurate classification, the samples that were classified as Lactobacillus spp. or as L. johnsonii (instead of L. acidophilus accordingly to API test) were sequenced again by using the pair of primers 27F/ 1492R that amplify the entire $16 \mathrm{~S}$ rRNA gene. The new results, also classified L. acidophilus biotype 3 IBNA, samples 27 and 51 as L. johnsonii. Instead, for the rest of the isolates the new BLAST analysis based on the complete 16S rRNA sequence confirmed the classification based on the API test (Table 2). Considering the 15 isolates identified from Lactobacillus genus, the following rank for frequency of species identification was registered: L. salivarius, $L$. acidophilus, and L. fermentum. After molecular identification, compared with the biochemical results, the six Lactobacillus isolates (IBNA 26, IBNA 64, IBNA 37, IBNA 29, IBNA 33, and IBNA 41) were identified and evaluated for desirable probiotic-related properties and their growth behavior fermentation process. The strains which were noted to have a significant resistance to low $\mathrm{pH}$, bile salts, antibiotics susceptibility were exposed for further assay. 


\subsection{Preservation of Bacterial Strains}

The long-time preservation (2 years) of Lactobacillus isolates strains was done in a selective medium with the addition of $20 \%$ glycerol. All strains can be found in the IBNA Balotesti Intern Collection under representative identification code (Table S1).

\section{4. $p H$ Low Tolerance}

The tolerance of Lactobacillus isolates confirmed and identified by 16S rRNA gene sequence analysis was tested for two levels of $\mathrm{pH}$ resistance ( $\mathrm{pH} 2.0$ and 3.0) during $3 \mathrm{~h}$ of incubation at $37^{\circ} \mathrm{C}$, in anaerobic conditions. The bacterial populations of identified strains (IBNA 26, IBNA 64, IBNA 29, IBNA 37, IBNA 33, and IBNA 41) were between 8-11 $\log 10$ in the fermentation medium with $\mathrm{pH} 6.5 \pm 0.2$. The low $\mathrm{pH}$ values of the fermentation medium (2.0 and 3.0) decreased the viable counts of confirmed Lactobacillus strains, involving a low resistance (Table 3).

Table 3. Viability of Lactobacillus isolates during $3 \mathrm{~h}$ of incubation at low $\mathrm{pH}$.

\begin{tabular}{|c|c|c|c|c|c|c|}
\hline \multirow{3}{*}{ Strains } & \multicolumn{6}{|c|}{ Exposure Time (h) } \\
\hline & \multicolumn{3}{|c|}{ pH 3.0} & \multicolumn{3}{|c|}{ pH 2.0} \\
\hline & $\mathbf{O h}$ & $1: 30 \mathrm{~h}$ & $3 \mathrm{~h}$ & $\mathbf{O h}$ & $1: 30 \mathrm{~h}$ & $3 \mathrm{~h}$ \\
\hline L. acidophilus IBNA 26 & $8.16^{\mathrm{a}}$ & $8.22^{a}$ & $6.56^{\mathrm{a}}$ & $5.26^{\mathrm{a}}$ & $0.00^{\mathrm{a}}$ & $0.00^{\circ}$ \\
\hline L. acidophilus IBNA 64 & $8.41^{\mathrm{a}}$ & $8.07^{\mathrm{a}}$ & $7.14^{\mathrm{b}}$ & $6.67^{\mathrm{b}}$ & $5.54^{\mathrm{b}}$ & $5.12^{\mathrm{b}}$ \\
\hline L. fermentum IBNA 37 & $8.34^{\mathrm{a}}$ & $9.04^{b}$ & $8.79^{c}$ & $7.73^{c}$ & $6.51^{b}$ & $5.13^{\mathrm{b}}$ \\
\hline L. salivarius IBNA 29 & $9.31^{b}$ & $9.09^{b}$ & $8.50^{c}$ & $7.26^{\mathrm{bc}}$ & $6.12^{b}$ & $5.26^{\mathrm{b}}$ \\
\hline L. salivarius IBNA 33 & $8.99^{b}$ & $8.13^{\mathrm{a}}$ & $7.64^{b}$ & $8.16^{\mathrm{c}}$ & $7.92^{c}$ & $7.72^{\mathrm{C}}$ \\
\hline L. salivarius IBNA 41 & $9.63^{c}$ & $9.38^{c}$ & $9.85^{\mathrm{d}}$ & $9.29^{d}$ & $8.18^{c}$ & $8.02^{c}$ \\
\hline \multicolumn{7}{|c|}{ Main effect } \\
\hline SEM & 0.14 & 0.13 & 0.26 & 0.30 & 0.66 & 0.63 \\
\hline$p$ value & $<0.0001$ & $<0.0001$ & 0.001 & $<0.0001$ & 0.001 & 0.002 \\
\hline
\end{tabular}

Results are expressed as means of three independent experiments each with duplicate. Means represent viable count $\left(\log _{10} \mathrm{CFU} \mathrm{mL}{ }^{-1}\right)$. ${ }^{\mathrm{a}-\mathrm{d}}$ Means with different superscripts in a separately column differ significantly $(p<0.05)$.

After measuring the viability at $\mathrm{pH} 3.0$, all confirmed LAB strains were able to survive during $3 \mathrm{~h}$ at $37{ }^{\circ} \mathrm{C}(\geq 58.53 \%)$. As shown in Table 3, at $\mathrm{pH} 2.0$ after $3 \mathrm{~h}$, the strains survivability compared with environment without acidic condition, involved a decline for IBNA $26(0.00 \%)$, IBNA $37(23.82 \%)$, and IBNA $29(10.22 \%)$. It was found to have an excellent survival rate at pH 2.0 for IBNA 41 (74.98\%), IBNA $33(65.90 \%)$, and IBNA $64(37.69 \%)$.

\subsection{Bile Salts Tolerance}

The viable counts of identified LAB strains were done at $0.3 \%$ bile salt, a concentration similar to that of human bile juice. Different results were obtained for strains viability after exposure to bile salt concentration (Table 4). IBNA 26 and IBNA 37 registered the lowest resistance after $3 \mathrm{~h}$, compared with IBNA 64, IBNA 29, IBNA 33, and IBNA 41 which exhibit resistance to bile salt.

Regarding the bile salt survivability, the effect of $0.3 \%$ bile salt involved different percentages of strains survivability with varying degrees. The strain IBNA 29 had around 90\% tolerance after $3 \mathrm{~h}$ in the presence of $0.3 \%$ bile salt, but at $\mathrm{pH} 2.0$, the survival rate declined. At the same time, IBNA 64 had adequate stability and showed $\geq 89.88 \%$ survivability after $3 \mathrm{~h}$.

Interestingly, from all identified and confirmed strains, after $3 \mathrm{~h}$, only L. acidophilus (IBNA 64) and L. salivarius (IBNA 33 and IBNA 41) involved higher probiotic resistance and were exposed to the spray-drying process to obtain the microencapsulated products as possible probiotics sources in animal feed. 
Table 4. Viability of Lactobacillus isolates during $3 \mathrm{~h}$ of incubation in $0.3 \%$ bile salt.

\begin{tabular}{cccc}
\hline Strains & \multicolumn{3}{c}{ Time (h) } \\
\cline { 2 - 4 } & $\mathbf{0 ~ h}$ & $\mathbf{1 : 3 0 ~ h}$ & $\mathbf{3 ~ h}$ \\
\hline L. acidophilus IBNA 26 & $8.04^{\mathrm{a}}$ & $0.00^{\mathrm{a}}$ & $0.00^{\mathrm{a}}$ \\
L. acidophilus IBNA 64 & $7.42^{\mathrm{b}}$ & $7.59^{\mathrm{b}}$ & $7.55^{\mathrm{b}}$ \\
L. fermentum IBNA 37 & $7.59^{\mathrm{b}}$ & $0.00^{\mathrm{a}}$ & $0.00^{\mathrm{a}}$ \\
L. salivarius IBNA 29 & $9.98^{\mathrm{c}}$ & $9.04^{\mathrm{c}}$ & $9.07^{\mathrm{c}}$ \\
L. salivarius IBNA 33 & $8.07^{\mathrm{a}}$ & $9.85^{\mathrm{d}}$ & $9.82^{\mathrm{d}}$ \\
L. salivarius IBNA 41 & $9.80^{\mathrm{cd}}$ & $9.79^{\mathrm{d}}$ & $8.79^{\mathrm{e}}$ \\
\hline SEM & 0.20 & 1.05 & 1.04 \\
\hline p value & $<0.001$ & $<0.0001$ & $<0.0001$ \\
\hline
\end{tabular}

Results are expressed as means of three independent experiments each with duplicate. Means represent viable count $\left(\log _{10} \mathrm{CFU} \mathrm{mL}{ }^{-1}\right)$. ${ }^{a-e}$ Means with different superscripts in a separately column differ significantly $(p<0.05)$.

\subsection{Hemolysis Test}

The present Lactobacillus strains were found to be nonhemolytic on a TSA agar plate after $24 \mathrm{~h}$ of incubation at $37^{\circ} \mathrm{C}$.

\subsection{Antibiotic Susceptibility}

The susceptibility profile of Lactobacillus isolates to usual antibiotics $(n=11)$ was evaluated (Table 5). All six LAB identified and confirmed both by API test and $16 \mathrm{~S}{ }_{\mathrm{r}}$ RNA showed $100 \%$ resistance to gentamicin, lincomycin, enrofloxacin, and streptomycin with higher sensitivity to penicillin. IBNA 29, IBNA 33, and IBNA 41 showed sensitivity to kanamycin and amikacin, while IBNA 26, IBNA 64, and IBNA 37 expressed resistance.

Table 5. Antibiotic susceptibility profile of LAB isolates.

\begin{tabular}{ccccccccccccccccc}
\hline \multicolumn{11}{c}{ Antibiotics Susceptibility } \\
\hline Strains & AMX & GN & K & MY & TE & P & VA & CT & DA & E & AK & C & OT & ENR & S & TIL \\
\hline 1 & I & R & R & R & R & S & I & I & R & I & R & R & S & R & R & I \\
2 & I & R & R & R & R & S & I & I & R & I & R & I & S & R & R & I \\
3 & S & R & R & R & S & S & I & R & I & I & R & S & S & R & R & R \\
4 & R & R & S & R & I & S & I & R & I & I & S & I & R & R & R & R \\
5 & R & R & S & R & I & S & I & R & I & I & S & I & R & R & R & R \\
6 & R & R & S & R & I & S & I & R & I & I & S & I & R & R & R & R \\
\hline
\end{tabular}

Where: amoxicillin (AMX) $25 \mu \mathrm{g}$; gentamicin (GN) $10 \mu \mathrm{g}$; kanamycin (K) $30 \mu \mathrm{g}$; lincomycin (MY) $10 \mu$; tetracycline (TE) $30 \mu \mathrm{g}$; penicillin (P) $10 \mu \mathrm{g}$; vancomycin (VA) $5 \mu \mathrm{g}$; colistin sulfate (CT) $10 \mu \mathrm{g}$; clindamycin (DA) $2 \mu \mathrm{g}$; erythromycin (E) $15 \mu \mathrm{g}$; amikacin (AK) $30 \mu \mathrm{g}$; chloramphenicol (C) $30 \mu \mathrm{g}$; oxytetracycline (OT) $30 \mu \mathrm{g}$; enrofloxacin (ENR) $5 \mu \mathrm{g}$; streptomycin (S) $10 \mu \mathrm{g}$; tilmicostin (TIL) $15 \mu \mathrm{g}$. Resistance (R): 0-5 mm; Intermediate (I): 6-25 mm; Sensitive (S): 26-35 mm. 1: L. acidophilus IBNA 26; 2: L. acidophilus IBNA 64; 3: L. fermentum IBNA 37; 4: L. salivarius IBNA 29; 5: L. salivarius IBNA 33; 6: L. salivarius IBNA 41.

\subsection{Bioreactor Batch and Fermentation Process}

The bacterial populations of L. salivarius (IBNA 33 and IBNA 41) and L. acidophilus IBNA 64 after fermentation in $2 \mathrm{~L}$ at laboratory-scale were $10.36 \pm 0.34,10.03 \pm 0.02$, and $8.32 \pm 0.33$, respectively. These strains were selected for the fermentation process and spray drying due to their ability to resist low $\mathrm{pH}$ and bile salt concentrations.

\subsection{Spray Drying Technique Using Maltodextrin and Glucose and Cell Viability}

Spray drying was applied only for three strains (L. salivarius IBNA 33, L. salivarius IBNA 41, and L. acidophilus IBNA 64), which registered significant resistance at low $\mathrm{pH}$ and bile salt concentrations before being submitted to the microencapsulated process as described in the Materials and Methods section. The powders that resulted in laboratoryscale drying were evaluated for cell viability. In order to improve the encapsulation process, dextrin and maltodextrin were used as polymers to increase the viability and maintain the 
stability of the probiotic cells during spray-drying. As can be observed, the spray drying conditions can affect Lactobacillus viability (Figure 1).

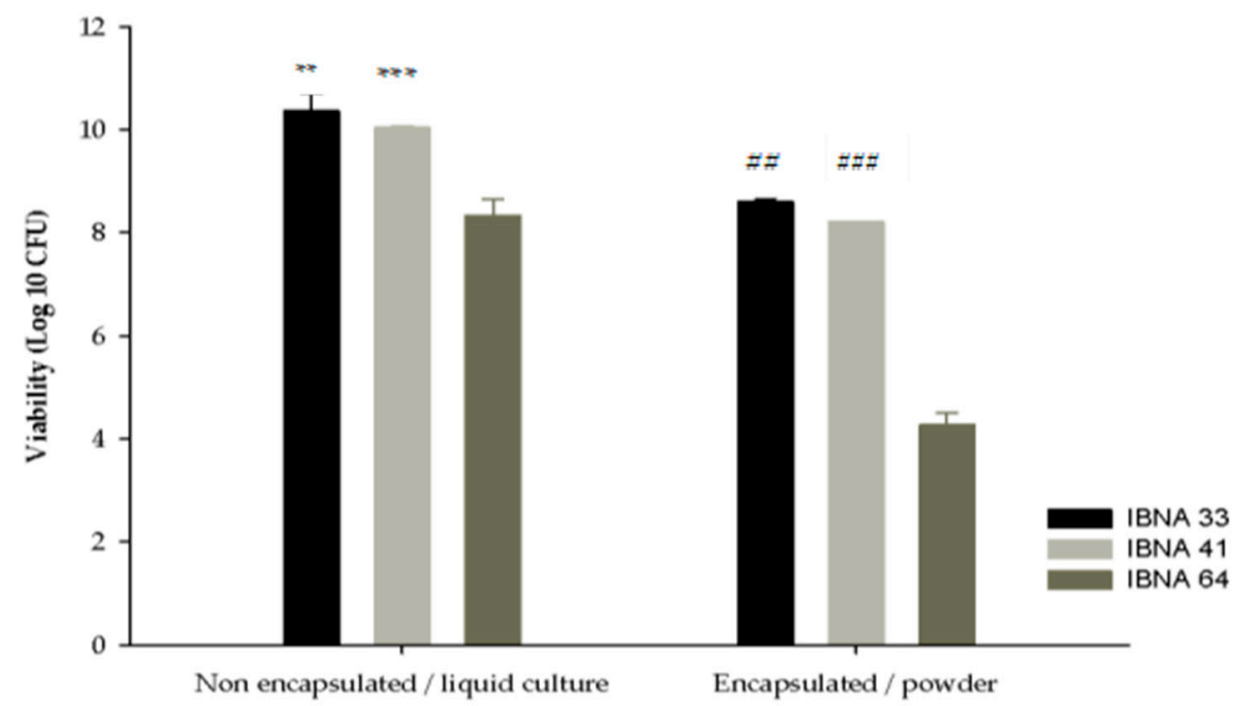

Figure 1. The bacterial population of L. salivarius (IBNA 33, IBNA 41) and L. acidophilus (IBNA 64) before and after spray drying process. Data are represented as means \pm standard error of means (SEM) of three independent experiments. ${ }^{* *} p<0.0001$ and ${ }^{* * *} p=0.0003$ compared with IBNA 64; \#\# $p=0.0159$ compared with IBNA 41 and \#\#\# $p<0.0001$ compared with IBNA 64 .

The thermal treatment of spray-drying $\left(66^{\circ} \mathrm{C}, 60 \mathrm{~min}\right)$ decreased the bacterial survival rate for L. acidophilus IBNA $64(p<0.0001)$, while L. salivarius (IBNA 33, around $80 \%$ and IBNA 41, around 78\%) strains were more resistant.

In the case of L. acidophilus IBNA 64, known as a thermo-sensitive probiotic strain, the viability was significantly different compared with the liquid form, where the survival was around $5 \%$ (remaining viable $\sim 2 \times 10^{4} \mathrm{CFU} \mathrm{g}^{-1}$ ). Instead, the impact of the spray drying on L. salivarius powders generated a $2 \mathrm{Log}$ ten-fold lowest viability as follows: IBNA 33 resisted around $80 \%$ (remaining viable $\sim 4 \times 10^{8} \mathrm{CFU} \mathrm{g}^{-1}$ ), with $78 \%$ for IBNA 41 (remaining viable $\sim 1.6 \times 10^{8} \mathrm{CFU} \mathrm{g}^{-1}$ ) vs. bacterial non-encapsulated culture.

Notably, no differences $(p>0.05)$ in the survival of cells were registered for L. salivarius strains, even if they were isolated from different areas of the poultry tract (IBNA 33 from cecum, respectively IBNA 41 from ileum) after exposure to high temperature of spray drying method.

\subsection{Probiotic Powder Storage}

Probiotic choice based on in vitro tests involves a representative selection for the application of the encapsulation process. After spray drying, the powders stability of strains (L. salivarius IBNA 33, L. salivarius IBNA 41, and L. acidophilus IBNA 64) was monitored at $0,7,14,21,27,35,42,49,56$, and 62 days. During storage, the cell viability of all encapsulated Lactobacillus strains weakly decreased. In the first month, both powders of L. salivarius (IBNA 33 and IBNA 41) registered constant survivability (Figure 2), and exhibited a growth rate of up to $75 \%$ during the first to 21 days, followed by decreases after 42 days. 


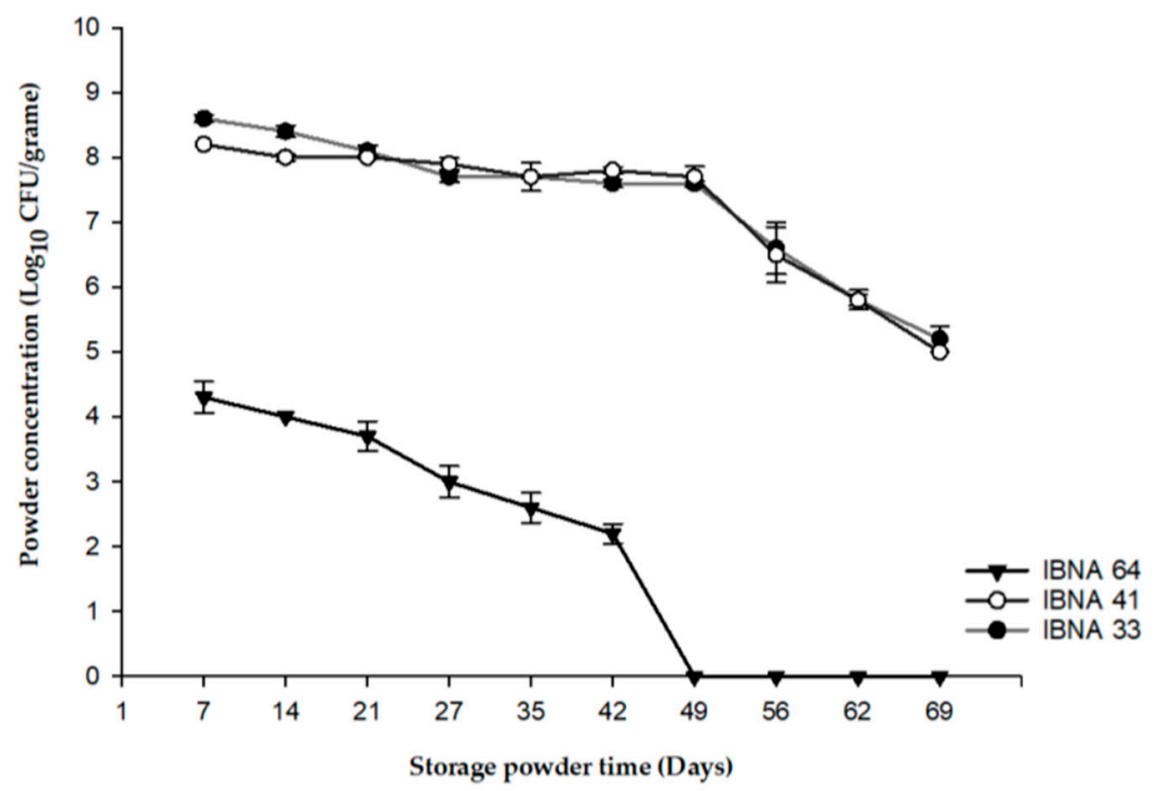

Figure 2. The storage stability of Lactobacillus (L. salivarius IBNA 33, L. salivarius IBNA 41, L. acidophilus IBNA 64) powders during 62 days at room temperature $\left(25^{\circ} \mathrm{C}\right)$. Data are represented as means \pm standard error of means (SEM) of three independent experiments.

A $3 \mathrm{Log}$ CFU g ${ }^{-1}$ reduction of viability was reached after 2 months of storage, when strains resisted around $65 \%$. In contrast, after spray drying, the viability of L. acidophilus IBNA 64 was reduced gradually after 7 days of storage at room temperature. Moreover, after 30 days, L. acidophilus IBNA 64 completely lost viability. We can affirm that the drying process displayed a decrease in viability, reaching a resistance around $87 \%$ for IBNA 33 , $95 \%$ for IBNA 41, and 3\% for IBNA 64 at 35 days of powder storage. These results showed that spray drying decreased the stability of Lactobacillus powders during the entire period of storage. Comparatively, with L. acidophilus IBNA 64 where a larger loss of viability was noted, the L. salivarius (IBNA 33 and IBNA 41) involved better stability. We can conclude that powders of L. salivarius (IBNA 33 and IBNA 41) were more stable than L. acidophilus IBNA 64.

\subsection{Total Coliforms Count}

In addition, as indicators of contamination, coliforms populations were determined in the powders of Lactobacillus strains after the spray drying process. The results confirmed that Lactobacillus strains in microencapsulated form did not record the presence of coliform bacteria.

\section{Discussion}

Based on phenotypical identification, some characteristics from some identified strains (IBNA 29, 33, 41, 48, 50, 51, 56, 57, 61) are reported in other studies [32,33].

To make a good selection of a bacterial strain to use as source of probiotic, it is necessary to provide preliminary in vitro screening by simulated of harvested conditions such as the high acidity of the stomach and high concentration of bile salts in the proximal intestine to ensure their safety [34].

LAB are indigenous microorganisms and a significant part of chicken GIT [35]. Considered dominant colonies of the small intestine and colon, LABs make an important contribution to balancing the intestinal animal microflora [36]. Furthermore, in poultry, administration of probiotics based on Lactobacillus spp. improves feed digestion, nutrient uptake, and growth performance [37,38].

The low $\mathrm{pH}$ resistance is one of the major probiotic selection factors, involving a reduction in the bacterial population at proventriculus and gizzard broiler chicks' area [38]. 
Parameters such as enzymes, high oxygen pressure, and bile salts are responsible for the reduction of microbial concentration, comparatively with the small and large intestine where the conditions are satisfactory for the growth of diverse bacteria [35]. Cecum and ileum areas are favorable for bacterial growth and have a concentration between $10^{7}-10^{11}$ bacteria per gram intestinal content $[32,33,39]$. The level of bacteria can change with animal age, environmental factors, and type of diet. Usually, the probiotics are administered in feed, water, or orally; they must have the ability to resist passage through the low $\mathrm{pH}$ of the gastric juice in the stomach and bile salts in the small intestine [5]. Based on the in vitro properties, the selected strains were tested on their tolerance to unfavorable conditions [40]. The $\mathrm{pH}$ and bile tolerance were evaluated for $3 \mathrm{~h}$ to predict the survival of the probiotic [40]. Interestingly, even though $16 S_{\mathrm{r}}$ RNA identification presented the same phenotypical profile, the isolates strains had different growth rates in response to $\mathrm{pH}$ and bile salt. As a condition, a probiotic bacteria needs to resist the passage through the stomach, where 1.5 to $2.0 \mathrm{pH}$ can be found, and into the intestinal tract [41]. In general, when evaluating the potential use of LAB as a probiotic, it is important to test their ability to tolerate bile salts [42], and from six candidates, only four strains survived in $0.3 \%$ concentration (Table 4 ).

There are three types of hemolysis, which are alpha, beta, and gamma hemolysis. To be safe for administration, the probiotics strains are necessary to be nonhemolytic (alpha hemolysis) [43]. In our trial, all isolates were alpha hemolytic.

All selected isolates were resistant to gentamicin, lincomycin, enrofloxacin, and streptomycin, with a susceptibility to amoxicillin, vancomycin, chloramphenicol, and clindamycin. These results are in agreement with those of Betancur et al. [42]. In line with Shazali et al. [44], who found that LAB isolated from broiler faces were found to be sensitive to penicillin and amoxicillin and resistant to ciprofloxacin and tetracycline, in our study IBNA 29, IBNA 33, and IBNA 41 showed sensitivity to kanamycin, while IBNA 26, IBNA 64, and IBNA 37 present resistance. Spray drying is an effective technique for the microencapsulation of probiotic bacteria such as lactic acid bacteria and sporulated bacilli, ensuring stability and viability during storage conditions compared to free bacteria [45]. Before microencapsulation, the viability of Lactobacillus strains (IBNA 33, IBNA 41, and IBNA 64) was $10^{8}-10^{10} \mathrm{CFU} / \mathrm{mL}$. This finding is affirmed by De Araujo et al. [45], who reported that bacteria growth depends on the drying temperature processes. To confer health benefits to the host, bacteria used as a probiotic source must present a viability $>7$ Log CFU/g [1]. A log reduction of two-to four-fold was observed after spray drying (Figure 2), signifying that strains' survivability diminished. Furthermore, the parameters such as air flow, mechanical processing, storage conditions, and encapsulated material can influence the survivability of bacteria [46]. Generally, obtaining Lactobacillus probiotic powder by spray drying implied a carrier media protection based on maltodextrin and protein sources [47]. Probiotic bacteria combined with the carrier matrix, should maintain some aspects (i.e., viability during storage, low $\mathrm{pH}$, resistance to bile salts and the digestive enzymes of the GIT), in order to reach the colon and to confer positive effects to the host" [46]. A good selection of carrier matrix can significantly improve the number of viable bacteria conferring protection during severe GIT conditions.

A previous study affirmed that bacteria cultures prepared with a matrix based on maltodextrin/skim milk powder (1:1) involve significant viable cell count (8 Log CFU/g); data are similar to $L$. salivarius strains from our report at 28 days of storage at room temperature. The viability of L. acidophilus IBNA 64 had an obvious decrease during spray drying in the presence of the maltodextrin/dextrin matrix. Similar data were reported, when the survival rates of L. acidophilus NCIMB 701748 were significantly $(p<0.001)$ affected by the composition of the carrier [45]. Unfortunately, the viability after the drying process is between $<1$ and $100 \%$ due to the drying parameter setting, different media conditions, and microorganism type $[48,49]$.

The Coliforms bacteria represent a major concern in controlling the probiotic LAB safety [46]. Our results are in accordance with Boor et al. [50], who affirmed that a quantity of coliforms less than 100 cell/mL was considered acceptable, but a count of less than 
10 cell $/ \mathrm{mL}$ is achievable and desirable. It suggests that after spray drying, the coliforms remained undetectable.

Spray drying is the most common dehydration method, as it has a low cost and is not time-consuming [51]. The decline and mortality of bacterial cell viability during the spray drying processing is probably caused by stress treatments [8], culture media, drying temperature, and water activity that impact not only the extent of thermal inactivation but also the loss of water bound on the cell surface [48]. Furthermore, the stability of microencapsulated bacteria is critically influenced by storage temperature, the exponential or stationary growth rate of the culture strains, physical state, growth stimulants, and thermoprotectant agents [46]. It was previously reported that different polysaccharides used for the microencapsulation of probiotics were proven to be an excellent way to conserve and protect the bacteria cells from harmful factors during spray drying processing [12,52].

\section{Conclusions}

In conclusion, from all LAB isolates, L. salivarius (IBNA 33 and IBNA 41) and L. acidophillus IBNA 64 had notably high probiotic properties. Microencapsulation using the spray drying process could maintain high viability for L. salivarius IBNA 33 and L. salivarius IBNA 41 compared to L. acidophilus IBNA 64 powders, where the rate of growth was lower. An interesting finding was that, before microencapsulation, L. salivarius (IBNA 33 and IBNA 41) satisfied all the requirements as a useful probiotic candidate, thus it could be used as a probiotic additive in animal nutrition.

Supplementary Materials: The following is available online at https:/ /www.mdpi.com/article/10 .3390/app11219867/s1, Table S1: Morphological, biochemical and percentage of identification by API 50 CHL, and ABIS online for Lactobacillus strains isolated from broiler chickens GIT.

Author Contributions: Conceptualization, original draft preparation, review and editing, data interpretation, investigation, formal analysis, methodology, funding acquisition, and Project administration, M.D., M.H. and G.C.; Formal analysis, methodology for spray drying process, D.C.V. and S.E.; Phenotypical and molecular identification for all isolates strains, investigation, and formal analysis, I.S., S.E.G. and A.D. All authors have read and agreed to the published version of the manuscript.

Funding: This research was funded by Ministry of Research Innovation and Digitization (grant number PN 19-09.01.04).

Institutional Review Board Statement: All procedures involving animals were approved by the Ethical Committee of the National Research Development Institute for Animal Biology and Nutrition, Romania (approval no. 1528/11.03.2020).

Informed Consent Statement: Not applicable.

Data Availability Statement: Data available from the corresponding author MD on reasonable request.

Conflicts of Interest: The authors declare no conflict of interest.

\section{References}

1. FAO Food Nutrition. Report of a Joint FAO/WHO Expert Consultation on Evaluation of Health and Nutritional Properties of Probiotics in Food including Powder Milk with Live. In Health and Nutrition Properties of Probiotics in Food Including Powder Milk with Live Lactic Acid Bacteria; FAO: Rome, Italy, 2006; p. 85.

2. Fuller, R. History and development of probiotics. In Probiotics; Springer: Dordrecht, The Netherlands, 1992; pp. 1-8. [CrossRef]

3. Dumitru, M.; Ciurescu, G.; Sorescu, I. In Vitro Evaluation of Some Probiotic Properties of Lactobacillus Strains Isolates from Chickens' gut. Sci. Pap. Anim. Sci. Biotechol. 2020, 53, 44-51.

4. Shehata, M.; El Sohaimy, S.; El-Sahn, M.A.; Youssef, M. Screening of isolated potential probiotic lactic acid bacteria for cholesterol lowering property and bile salt hydrolase activity. Ann. Agric. Sci. 2016, 61, 65-75. [CrossRef]

5. Bujnakova, D.; Strakova, E.; Kmet, V. In vitro evaluation of the safety and probiotic properties of Lactobacilli isolated from chicken and calves. Anaerobe 2014, 29, 118-127. [CrossRef]

6. A De Melo, W.C.M.; Avci, P.; De Oliveira, M.N.; Gupta, A.; Vecchio, D.; Sadasivam, M.; Chandran, R.; Huang, Y.; Yin, R.; Perussi, L.R.; et al. Photodynamic inactivation of biofilm: Taking a lightly colored approach to stubborn infection. Expert Rev. Anti-Infect. Ther. 2013, 11, 669-693. [CrossRef] 
7. Pradipta, M.S.I.; Harimurti, S.; Widodo, W. Feed Supplementation with Encapsulated Indigenous Probiotic Lactic Acid Bacteria Increased Broiler Chicken Performance. ASEAN J. Sci. Technol. Dev. 2019, 36, 29-34. [CrossRef]

8. Harimurti, S.; Hadisaputro, W. Effect of Indigenous Probiotics Lactic Acid Bacteria on Performance, Intestinal Length and Weight of Internal Organs of Broiler Chicken. In Proceedings of the International Conference on Beneficial Microbes, Penang, Malaysia, 27-29 May 2014; pp. 179-181.

9. Mahmoud, M.; Abdallah, N.A.; El-Shafei, K.; Tawfik, T.N.; El-Sayed, H. Survivability of alginate-microencapsulated Lactobacillus plantarum during storage, simulated food processing and gastrointestinal conditions. Heliyon 2020, 6, e03541. [CrossRef]

10. Pop, O.L.; Diaconeasa, Z.; Thorsten, B.; Ciuzan, O.; Pamfil, D.; Vodnar, D.C.; Socaciu, C. Effect of Glycerol, as Cryoprotectant in the Encapsulation and Freeze Drying of Microspheres Containing Probiotic Cells. Bull. Univ. Agric. Sci. Vet.-Med. Cluj-Napoca Food Sci. Technol. 2015, 72, 27-32. [CrossRef]

11. Sahadeva, R.P.K.; Leong, S.F.; Chua, K.H.; Tan, C.H.; Chan, H.Y.; Tong, E.V.; Wong, S.Y.; Chan, H.K. Survival of commercial probiotic strains to $\mathrm{pH}$ and bile. Int. Food Res. J. 2011, 18, 1515-1522.

12. Tripathi, M.; Giri, S. Probiotic functional foods: Survival of probiotics during processing and storage. J. Funct. Foods 2014, 9, 225-241. [CrossRef]

13. Canadian Food Inspection Agency (CFIA). Probiotic Claims. 2009. Chapter 8, Section 8.7. Available online: http://www. inspection.gc.ca/english/fssa/labeti/guide/ch8ae.html200 (accessed on 12 October 2021).

14. El-Salam, M.H.A.; El-Shibiny, S. Preparation and properties of milk proteins-based encapsulated probiotics: A review. Dairy Sci. Technol. 2015, 95, 393-412. [CrossRef]

15. Soukoulis, C.; Behboudi-Jobbehdar, S.; Yonekura, L.; Parmenter, C.D.J.; Fisk, I.D. Impact of Milk Protein Type on the Viability and Storage Stability of Microencapsulated Lactobacillus acidophilus NCIMB 701748 Using Spray Drying. Food Bioproces. Technol. 2013, 7, 1255-1268. [CrossRef]

16. Mu, R.-J.; Yuan, Y.; Wang, L.; Ni, Y.; Li, M.; Chen, H.; Pang, J. Microencapsulation of Lactobacillus acidophilus with konjac glucomannan hydrogel. Food Hydrocoll. 2018, 76, 42-48. [CrossRef]

17. Chew, S.C.; Tan, C.H.; Pui, L.P.; Chong, P.N.; Gunasekaran, B.; Nyam, K.L. Encapsulation technologies: A tool for func-tional foods development. Int. J. Innov. Technol. Explor. Eng. 2019, 8, 154-160.

18. Bhagwat, A.; Bhushette, P.; Annapure, U.S. Spray drying studies of probiotic Enterococcus strains encapsulated with whey protein and maltodextrin. Beni-Suef Univ. J. Basic Appl. Sci. 2020, 9, 1-8. [CrossRef]

19. Yao, M.; Xie, J.; Du, H.; McClements, D.J.; Xiao, H.; Li, L. Progress in microencapsulation of probiotics: A review. Compr. Rev. Food Sci. Food Saf. 2020, 19, 857-874. [CrossRef]

20. Song, C.E.; Shim, H.H.; Kuppusamy, P.; Jeong, Y.-I.; Lee, K.D. Potential Sustainable Properties of Microencapsulated Endophytic Lactic Acid Bacteria (KCC-42) in In-Vitro Simulated Gastrointestinal Juices and Their Fermentation Quality of Radish Kimchi. BioMed Res. Int. 2018, 2018, 6015243. [CrossRef]

21. Harimurti, S.; Huda, M.; Kristiani, A.D. The dynamics of indigenous lactic acid bacteria probiotics on carcass yield, ab-dominal fat and intestinal morphology of broilers. In Proceedings of the 3rd AINI International Seminar, Padang, Indonesia, 24-25 September 2013; Indonesian Association of Nutrition and Feed Science: Padang, Indonesia, 2013; pp. 185-188.

22. Zheng, J.; Wittouck, S.; Salvetti, E.; Franz, C.M.; Harris, H.M.; Mattarelli, P.; O’Toole, P.W.; Pot, B.; Vandamme, P.; Walter, J.; et al. A taxonomic note on the genus Lactobacillus: Description of 23 novel genera, emended description of the genus Lactobacillus Beijerinck 1901, and union of Lactobacillaceae and Leuconostocaceae. Int. J. Syst. Evol. Microbiol. 2020, 70, 2782-2858. [CrossRef]

23. Sorescu, I.; Dumitru, M.; Ciurescu, G. Lactobacillus spp. and Enterococcus faecium strains isolation, identification, preservation and quantitative determinations from turkey gut content. Rom. Biotechnol. Lett. 2019, 24, 41-49. [CrossRef]

24. Dumitru, M.; Tabuc, C.; Jurcoane, S. Obtaining a feed additive based of Lactobacillus plantarum strain. Sci. Pap. Ser. A Agron. 2018, 61, 115-122.

25. Vanhoutte, T.; Huys, G.; De Brandt, E.; Swings, J. Temporal stability analysis of the microbiota in human feces by denaturing gradient gel electrophoresis using universal and group-specific 16S rRNA gene primers. FEMS Microbiol. Ecol. 2004, 48, 437-446. [CrossRef] [PubMed]

26. Al Kaabi, H.K.J.; Al-Yassari, A.K.S. 16SrRNA sequencing as tool for identification of Salmonella spp. isolated from human diarrhea cases. J. Phys. Conf. Ser. 2019, 1294, 062041. [CrossRef]

27. Shokryazdan, P.; Sieo, C.C.; Kalavathy, R.; Liang, J.B.; Alitheen, N.B.; Jahromi, M.F.; Ho, Y.W. Probiotic Potential of Lactobacillus Strains with Antimicrobial Activity against Some Human Pathogenic Strains. BioMed Res. Int. 2014, 2014, 1-16. [CrossRef]

28. Ritter, A.C.; Paula, A.; Correa, F.; Veras, F.F.; Brandelli, A. Characterization of Bacillus subtilis available as probiotics. J. Microbiol. Res. 2018, 8, 23-32. [CrossRef]

29. Dumitru, M.; Sorescu, I.; Habeanu, M.; Tabuc, C.; Idriceanu, L.; Jurcoane, S. Preliminary characterisation of Bacillus subtilis strain use as a dietary probiotic bio-additive in weaning piglet. Food Feed. Res. 2018, 45, 203-211. [CrossRef]

30. Dumitru, M.; Sorescu, I.; Habeanu, M.; Tabuc, C.; Jurcoane, S. Preliminary characterization in vitro of Bacillus licheniformis strain for used as dietary probiotic. Sci. Bull. Ser. F. Biotechnol. 2019, 23, 64-172.

31. Salman, A.M.A.; Hamad, M. Enumeration and identification of Coliform bacteria from raw milk in Khartoum State, Sudan. J. Cell Anim. Biol. 2011, 5, 121-128.

32. Sorescu, I.; Dumitru, M.; Ciurescu, G. Lactobacillus spp. Strains Isolation, Identification, Preservation and Quantitative Determinations from Gut Content of 45-Day-Old Chickens Broilers. Braz. J. Poult. Sci. 2021, 23, 1-8. [CrossRef] 
33. Saumitou-Laprade, P.; Vernet, P.; Vekemans, X.; Castric, V.; Barcaccia, G.; Khadari, B.; Baldoni, L. Controlling for genetic identity of varieties, pollen contamination and stigma receptivity is essential to characterize the self-incompatibility system of Olea europaea L. Evol. Appl. 2017, 10, 860-866. [CrossRef]

34. Musikasang, H.; Tani, A.; H-Kittikun, A.; Maneerat, S. Probiotic potential of lactic acid bacteria isolated from chicken gastrointestinal digestive tract. World J. Microbiol. Biotechnol. 2009, 25, 1337-1345. [CrossRef]

35. Yadav, S.; Jha, R. Strategies to modulate the intestinal microbiota and their effects on nutrient utilization, performance, and health of poultry. J. Anim. Sci. Biotechnol. 2019, 10, 2. [CrossRef] [PubMed]

36. Tambekar, D.H.; Bhutada, S.A. Studies on antimicrobial activity and characteristics of bacteriocins produced Lactobacillus strains isolated from milk of domestic animals. Internet J. Microbiol. 2010, 8, 1-6.

37. Noohi, N.; Papizadeh, M.; Rohani, M.; Talebi, M.; Pourshafie, M.R. Screening for probiotic characters in lactobacilli isolated from chickens revealed the intra-species diversity of Lactobacillus brevis. Anim. Nutr. 2020, 7, 119-126. [CrossRef] [PubMed]

38. Ciurescu, G.; Dumitru, M.; Gheorghe, A.; Untea, A.; Drăghici, R. Effect of Bacillus subtilis on growth performance, bone mineralization, and bacterial population of broilers fed with different protein sources. Poult. Sci. 2020, 99, 5960-5971. [CrossRef]

39. Gheorghe, A.; Lefter, N.A.; Idriceanu, L.; Ropotă, M.; Hăbeanu, M. Effects of dietary extruded linseed and Lactobacillus acidophilus on growth performance, carcass traits, plasma lipoprotein response, and caecal bacterial populations in broiler chicks. Ital. J. Anim. Sci. 2020, 19, 822-832. [CrossRef]

40. Guo, X.-H.; Kim, J.-M.; Nam, H.-M.; Park, S.-Y.; Kim, J.-M. Screening lactic acid bacteria from swine origins for multistrain probiotics based on in vitro functional properties. Anaerobe 2010, 16, 321-326. [CrossRef]

41. Sayan, H.; Assavacheep, P.; Angkanaporn, K.; Assavacheep, A. Effect of Lactobacillus salivarius on growth performance, diarrhea incidence, fecal bacterial population and intestinal morphology of suckling pigs challenged with F4+ enterotoxigenic Escherichia coli. Asian-Australas. J. Anim. Sci. 2018, 31, 1308-1314. [CrossRef]

42. Betancur, C.; Martínez, Y.; Tellez-Isaias, G.; Avellaneda, M.C.; Velázquez-Martí, B. In Vitro Characterization of Indigenous Probiotic Strains Isolated from Colombian Creole Pigs. Animals 2020, 10, 1204. [CrossRef]

43. Reuben, R.; Roy, P.; Sarkar, S.; Alam, A.R.U.; Jahid, I. Characterization and evaluation of lactic acid bacteria from indigenous raw milk for potential probiotic properties. J. Dairy Sci. 2020, 103, 1223-1237. [CrossRef]

44. Shazali, N.; Foo, H.L.; Loh, T.C.; Choe, D.W.; Rahim, R.A. Prevalence of antibiotic resistance in lactic acid bacteria isolated from the faeces of broiler chicken in Malaysia. Gut Pathog. 2014, 6, 1-7. [CrossRef]

45. De Araujo-Uribe, N.; Ruiz-Villadiego, O.S.; Montoya-Campuzano, O.I.; Ramírez-Gutiérrez, L.A. Viability of probiotic bacteria Bacillus polymyxa, Bacillus megaterium and Lactobacillus delbruekii subsp. bulgaricus microencapsulated under the spray-drying technique. DYNA 2018, 85, 272-276. [CrossRef]

46. Yonekura, L.; Sun, H.; Soukoulis, C.; Fisk, I. Microencapsulation of Lactobacillus acidophilus NCIMB 701748 in matrices containing soluble fibre by spray drying: Technological characterization, storage stability and survival after in vitro digestion. J. Funct. Foods 2013, 6, 205-214. [CrossRef] [PubMed]

47. Lapsiri, W.; Bhandari, B.; Wanchaitanawong, P. Viability of Lactobacillus plantarum TISTR 2075 in Different Protectants during Spray Drying and Storage. Dry. Technol. 2012, 30, 1407-1412. [CrossRef]

48. Fu, N.; Chen, X.D. Towards a maximal cell survival in convective thermal drying processes. Food Res. Int. 2011, 44, 1127-1149. [CrossRef]

49. Huang, S.; Méjean, S.; Rabah, H.; Dolivet, A.; Le Loir, Y.; Chen, X.D.; Jan, G.; Jeantet, R.; Schuck, P. Double use of concentrated sweet whey for growth and spray drying of probiotics: Towards maximal viability in pilot scale spray dryer. J. Food Eng. 2016, 196, 11-17. [CrossRef]

50. Boor, K.; Brown, D.; Murphy, S.; Kozlowski, S.; Bandler, D. Microbiological and Chemical Quality of Raw Milk in New York State. J. Dairy Sci. 1998, 81, 1743-1748. [CrossRef]

51. Zhang, Y.; Lin, J.; Zhong, Q. Effects of media, heat adaptation, and outlet temperature on the survival of Lactobacillus salivarius NRRL B-30514 after spray drying and subsequent storage. LWT 2016, 74, 441-447. [CrossRef]

52. Calinoiu, L.F.; Vodnar, D.; Precup, G. A Review: The Probiotic Bacteria Viability under Different Conditions. Bull. Univ. Agric. Sci. Vet.-Med. Cluj-Napoca Food Sci. Technol. 2016, 73, 55-60. [CrossRef] 